\title{
Selenium (IV), selenium (VI) and organic selenium in Lake Biwa, the Yodo River and Osaka Bay
}

\author{
YuZURU NAKaguchi and Keizo Hiraki \\ Department of Chemistry, Faculty of Science and Technology, Kinki University, \\ 3-4-1 Kowakae, Higashiosaka, 577 Japan
}

(Received January 14, 1993; Accepted July 26, 1993)

\begin{abstract}
Selenium in natural waters was chemically specified at 16 stations from Lake Biwa to Osaka Bay. The concentrations of selenium (IV), selenium (VI) and organic selenium in Lake Biwa ranged from 0.04 to 0.36 , from 0.00 to 0.36 , and from 0.00 to $1.97 \mathrm{nM}$, respectively. The concentration of organic selenium was highest at the depth of the maximal of chlorophyll a concentration in the Lake Biwa water. The concentrations of selenium (IV), selenium (VI) and organic selenium in the Yodo River ranged from 0.12 to 0.37 , from 0.02 to 0.32 , and from 0.32 to $0.18 \mathrm{nM}$, respectively. In coastal Osaka Bay, the concentrations of selenium (IV), selenium (VI) and organic selenium ranged from 0.05 to 0.31 , from 0.09 to 0.50 , and from 0.14 to $0.77 \mathrm{nM}$, respectively.
\end{abstract}

\section{INTRODUCTION}

Lake Biwa water flows out into the Seta River, meets other tributaries, such as the Katsura, Kamo and Kizu Rivers, finally becoming the Yodo River. This river, which supplies water for ten million people and for industries in the Kinki area, finally flows out into Osaka Bay. In recent years, Lake Biwa water has come to be polluted by eutrophication due to an inflow of agricultural and industrial waste waters. Every summer, the annual appearance of nanoplankton such as Microcystis causes drinking water to have an offensive odor. The annual blooming of nanoplankton is thought to result from the high concentration of nutrients and vitamin $\mathrm{B}_{12}$ (Yamochi, 1983; Nakamura et al., 1989). However, selenium was recently reported to be a growth rate-limiting factor for Gymnodinium nagasakiense, a red tide alga (Ishimaru et al., 1989). The studies on selenium in natural water have been mainly on its chemical speciation in sea water. Several investigators have reported that selenium is present in three chemical forms, such as selenium (IV), selenium (VI) and organic selenium
(Sugimura and Suzuki, 1985; Takayanagi and Wong, 1985; Cutter and Bruland, 1984; Nakaguchi et al., 1985; Aono et al., 1991). The vertical distribution of selenium (IV) was similar to those of nitrate + nitrite and phosphate which is contained in the phytoplankton cell and thus the behavior of selenite in sea water might be related with marine phytoplankton activities (Aono et al., 1991). In addition, a fractional determination method was established for detailed speciation of organic selenium. This was applied to the determination of organic selenium in sea water samples collected from the Bering Sea. Using this method, the concentration of selenium in the amino acid fraction (selenoamino acid) was found to range from 4.18 to $21.0 \mathrm{pM}$ and that of selenium in the organic acid fraction (organic acid-bound selenium) from 4.94 to $12.9 \mathrm{pM}$ (Aono et al., 1990). The behavior and speciation of selenium in sea water was closely related with the activities of various microorganisms. In fact, a few reports have addressed the issue of selenium in rivers and estuaries (Measures and Burton, 1978; Takayanagi and Wong, 1984; Takayanagi and Cossa, 1985; Takayanagi and Benlzile, 1988). 
However, the behavior and speciation of trace elements, which are influenced by microorganism activities, as well as their valence states, vary with the environmental condition.

Sugiyama et al. (1986) reported the concentrations of trace metals in Lake Biwa determined by a solvent extraction-ICP method. However, the concentration of selenium was below the detection limit in all samples. Therefore the geochemical cycle of selenium in Lake Biwa remains unknown.

We examined the concentrations of selenium species in Lake Biwa, the Yodo River and Osaka Bay, and the diurnal variation of selenium species in Osaka Bay using a fluorometric method (Nakaguchi et al., 1985).

\section{Study Area}

Lake Biwa, which is located in the center of Honshu Island, is the largest lake in Japan. Lake Biwa has a water volume of about $270 \times 10^{8} \mathrm{~cm}^{3}$, and supplies drinking water to $1 \times 10^{7}$ people in Kinki area (Fujinaga and Hori, 1982). The lake consists of a main basin (the north lake), with a surface area of $623 \mathrm{~km}^{2}$ and a mean depth of 41 $\mathrm{m}$, and a subbasin (the south lake) of $58 \mathrm{~km}^{2}$ in area and $3.6 \mathrm{~m}$ in a mean depth (Kotoda and Mizuyama, 1984). The water temperature is usually stratified except in the winter, and a thermocline develops during summer and autumn. The distribution of the water-mass may depend upon that of the water-density, which in turn is a function of temperature (Okamoto, 1984). As a result, movement of water-mass influences the flux and distribution of microorganisms all year round.

\section{Sampling and Analyticai METHODS}

Figure 1 shows the sampling sites. Water samples were collected at station 1 on 8 July and 24 November, 1981, and 30 March and 7 May, 1982, at stations 2 through 4 on 3 June 1981, at stations 5 through 10 on 20 October, 1981, at stations 11 through 14 on 18 September, 1982, at station 15 on $30 \mathrm{July,} 1982$, and at station 16 on 27 November, 1982. The water was collected in a 3-liter Van Done water sampler and in a Kitahara water sampler for measurement of water temperature. The bottom water was collected at above one meter of the bottom. The water was immediately filtered through 3.0 and then $0.3 \mu \mathrm{m}$ Toyo membrane filters. The filtrates were stored in polyethylene bottles, kept in ice, and returned to the laboratory on the same day. The water was treated for the determination of selenium within five hours after sampling.

The analytical method used to determine selenium (IV), selenium (VI) and organic selenium was described previously (Nakaguchi $e t$ $a l .$, 1985). The recommended procedure is summarized as follows. The selenium (IV) content in the water was determined by 2,3-diaminonaphthalene (DAN) fluorometry. The amount of selenium (VI) was estimated by subtracting the amount of selenlum (IV) from the sum of selenium (IV) and selenium (VI) which was obtained by DAN fluorometry after the $\mathrm{KBr}$ reduction procedure. The amount of organic selenium was estimated by subtracting the amounts of both selenium (IV) and selenium (VI) from the total amount of selenlum, which was determined by the coprecipitation method using tellurium, followed by DAN fluorometry.

Chlorophyll a was determined by spectrometry using a glass fiber filter (GC-50) through which the water was filtered. The concentration of chlorophyll a was calculated by the formula described by Strickland and Parsons (1972). The dissolved oxygen was determined by the titrimetric method (Carpenter, 1965). The chlorinity was determined by laboratory titratlon as described by Strickland and Parsons (1972).

\section{Results AND Discussion}

Selenium (IV), selenium (VI) and organic selenium in Lake Biwa

Figure 2 shows the vertical profiles of water temperature, dissolved oxygen and chlorophyll a at station 1 on 8 July and 24 November 1981, 


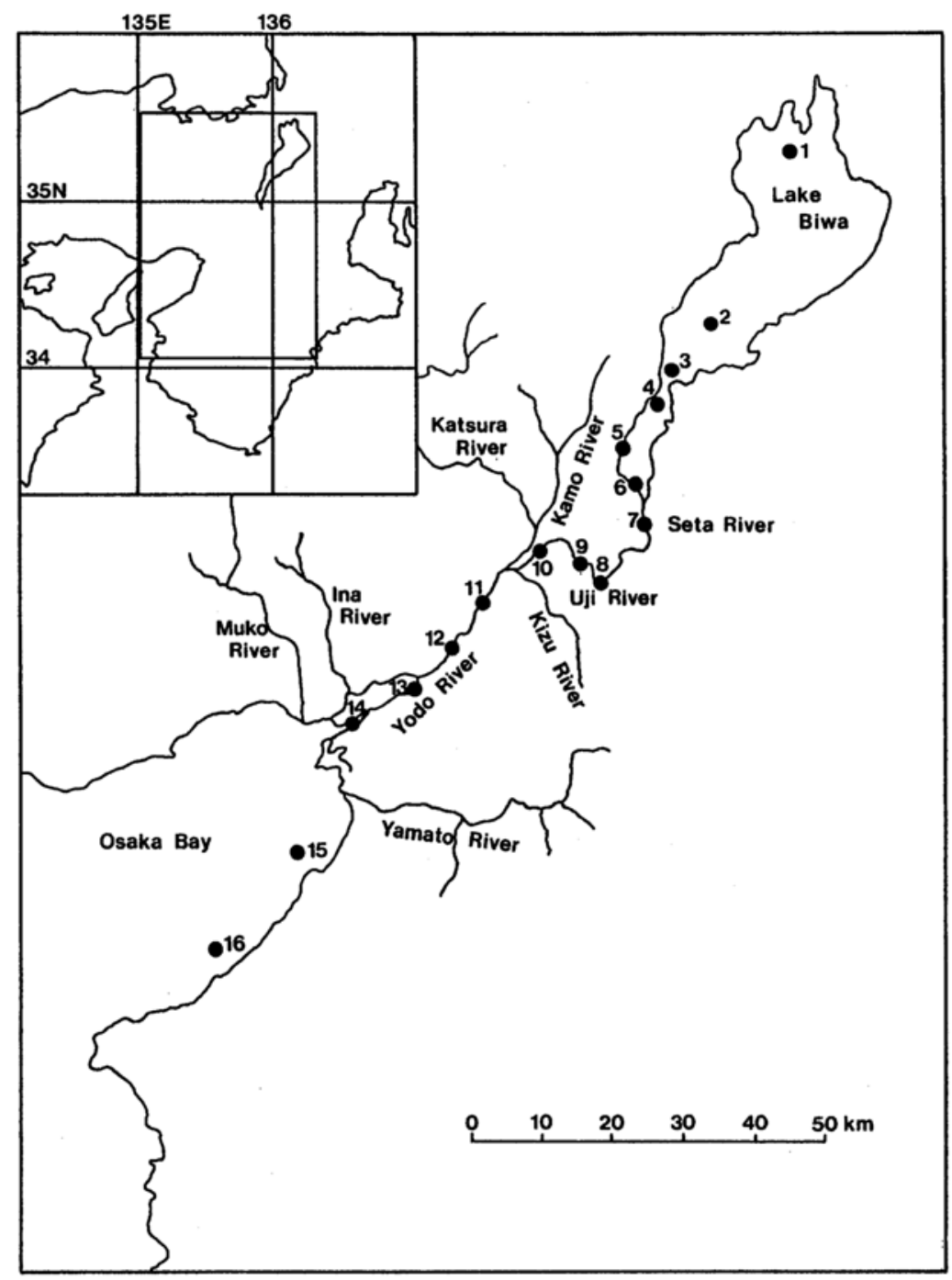

Fig. 1. Location of sampling stations.

and Fig. 3 those of selenium (IV), selenium (VI) and organic selenium at station 1 .

The behavior and distribution of selenium at station 1 is summarized as follows: The vertical distribution of inorganic selenium (IV) and (VI) was uniform in November 1981, March and May 1982 , when there was no stratification in water column. However, in July when the thermocline appeared, the concentration of selenium (IV) was slightly lower and that of selenium (VI) higher at the depth where the chlorophyll a concentration was maximal. Except in November, the concentration of organic selenium was highest at the depth of the maximal chlorophyll a concentration. These findings suggest that organic selenium may be supplied by excretion of phytoplankton. At station 2, the vertical variations of both inorganic selenium (IV) and selenium (VI) were smaller than that of organic selenium. The concentration maximum of organic selenium appeared at $20 \mathrm{~m}$. The vertical distribution of organic selenium was not similar to that of chlorophyll a.

On the other hand, a rapid increase of organic selenium at the bottom of the lake was observed in July 1981. Organic selenium can be supplied not only by excretion of phytoplankton but also by other sources, for example, regenera- 


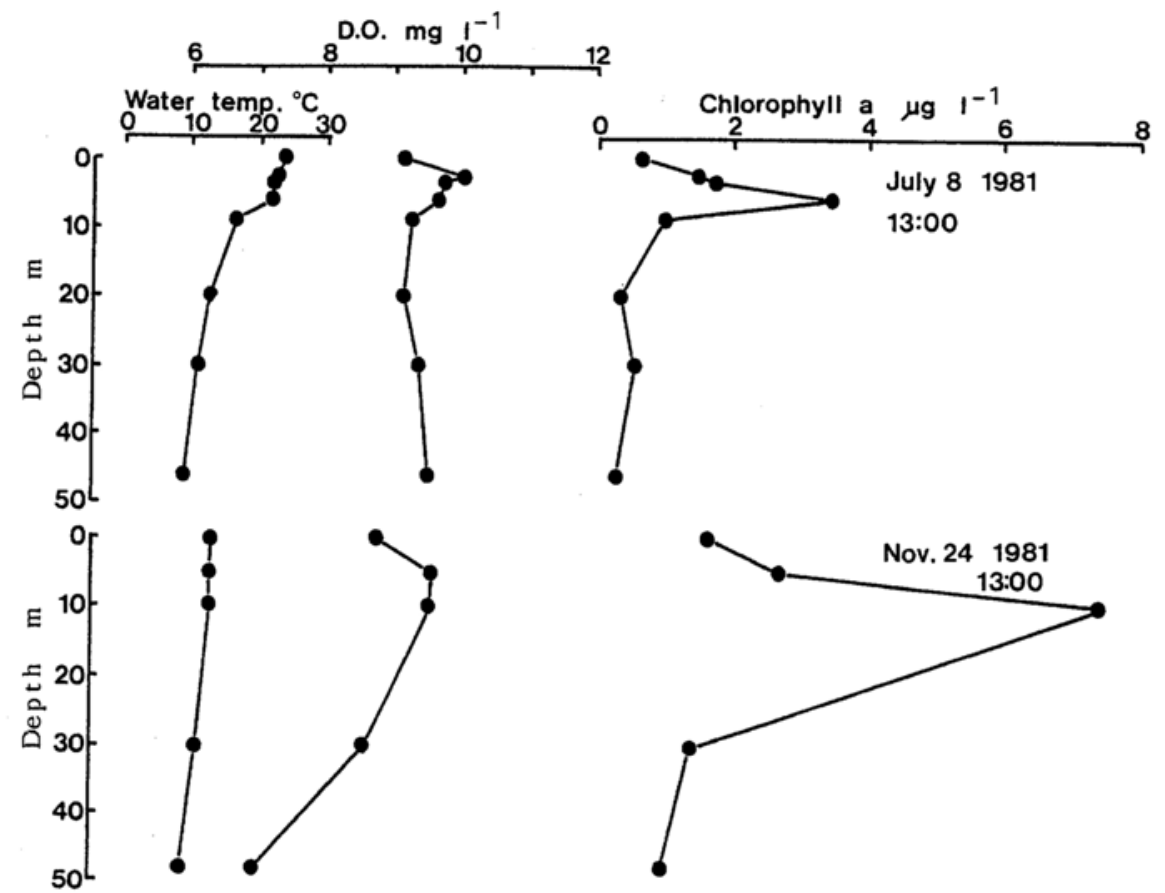

Fig. 2. Vertical distributions of water temperature, dissolved oxygen and chlorophyll a at station 1.
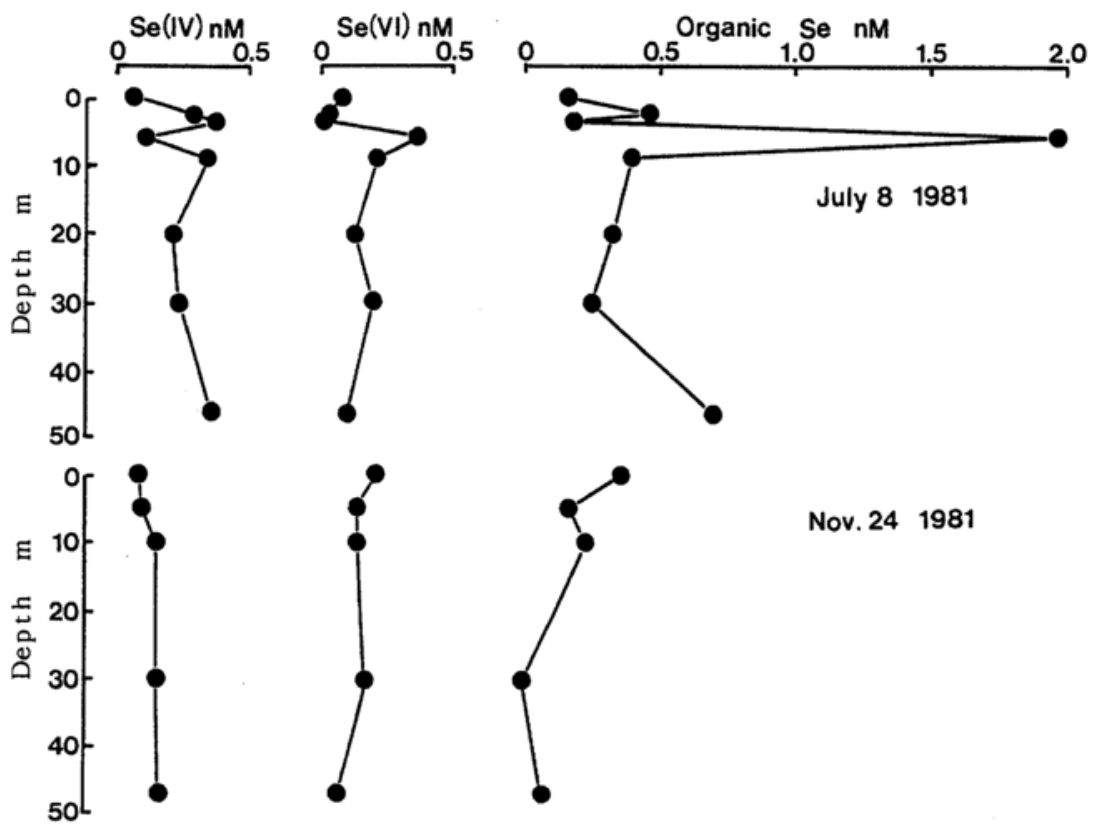

Nov. 241981

Fig. 3. Vertical distributions of selenium (IV), selenium (VI) and organic selenium at station 1.

tion and/or release from sediment. The regeneration mechanism of organic selenium from sediment to bottom water remains uncertain and will be clarified in the future.

\section{Distribution of selenium in the Yodo River}

Horizontal distribution of selenium (IV), selenium (VI), organic selenium and chlorophyll a from the surface of the south basin of Lake 

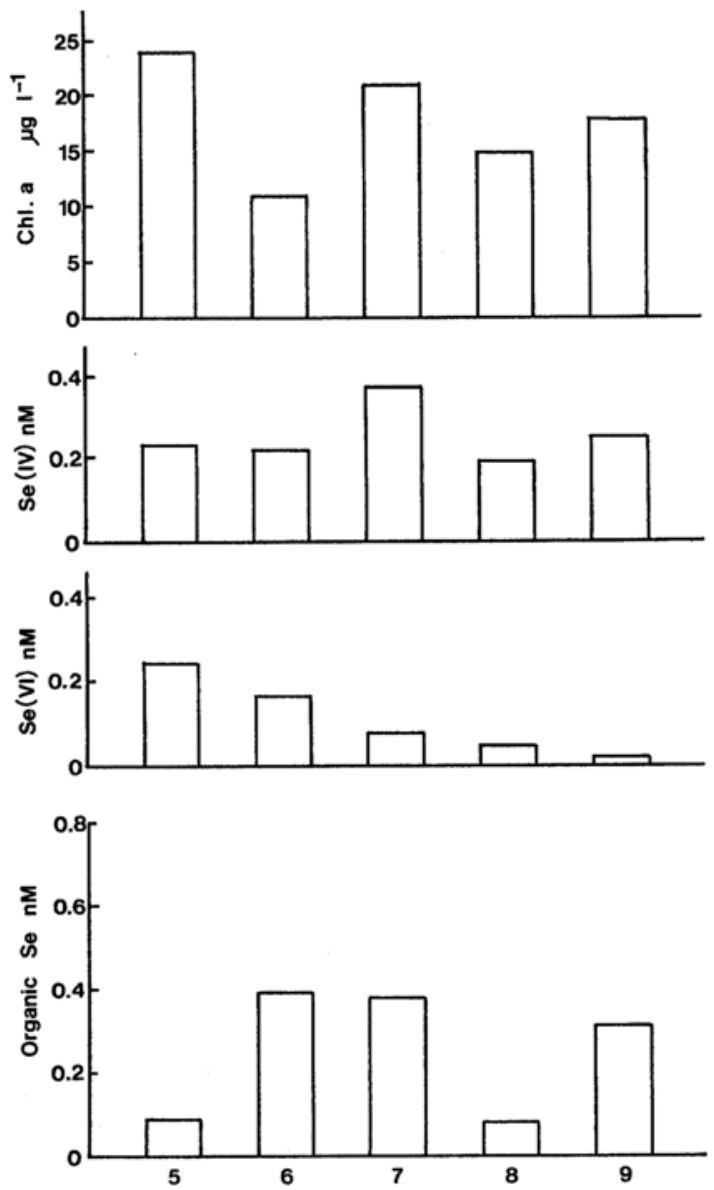

Fig. 4. The concentration variations of selenium (IV), selenium (VI), organic selenium and chlorophyll a from station 5 to 9.

Biwa (station 5) to Osaka Bay (station 14) are shown in Figs. 4 and 5.

The average concentrations of selenium (IV), selenium (VI) and organic selenium in the Yodo River were $0.22,0.11$ and $0.44 \mathrm{nM}$, respectively. Organic selenium occupied about $57 \%$ of the total dissolved selenium. The concentration of selenium (IV) temporarily increased at the Seta River (station 7). However, the variation was comparatively small at all sampling points. The concentration of selenium (VI) decreased gradually from $0.25 \mathrm{nM}$ at station 5 to $0.02 \mathrm{nM}$ at station 9. The variation range of the concentration of organic selenium was larger than that of inorganic selenium. The concentration of organic selenium from station 10 to 14 was high. Possible sources of organic selenium in the Yodo
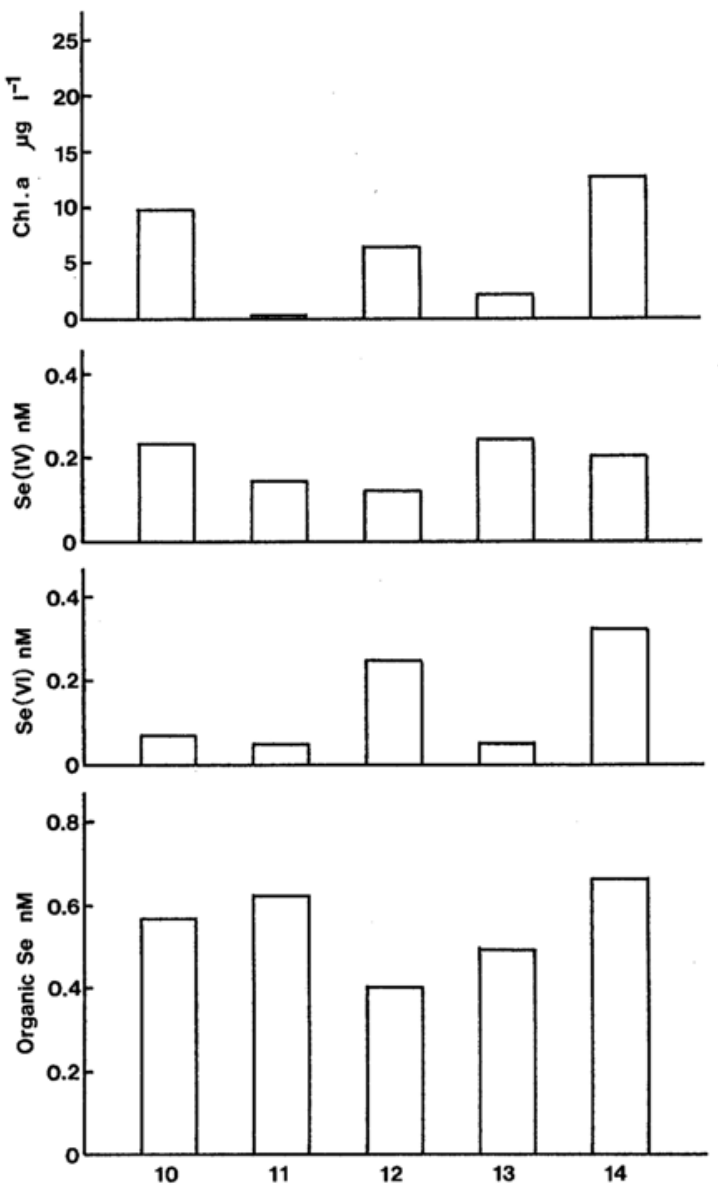

Fig. 5. The concentration variations of selenium (IV), selenium (VI), organic selenlum and chlorophyll a from station 10 to 14.

River include release from sediment and waste waters. Various industrial and agricultural waste waters flow into the Yodo River. Thus organic selenium may be supplied by waste water. However inorganic selenium compounds are widely used for industrial materials (Lansche, 1967). Thus inorganic selenium may be supplied by industrial waste water and then reduced to organic form in anaerobic sediment. It is necessary to determine the selenium species in industrial waste water to identify the source of selenium in Yodo river. On the other hand, a temporary increase of selenium (VI) was recognized at the estuary (St. 14, salinity: $15.54 \%$ ), and the concentration ratio of selenium (IV) to selenium (VI) decreased from 4.80 at St. 13 to 0.30 at the surface of St. 15 . 

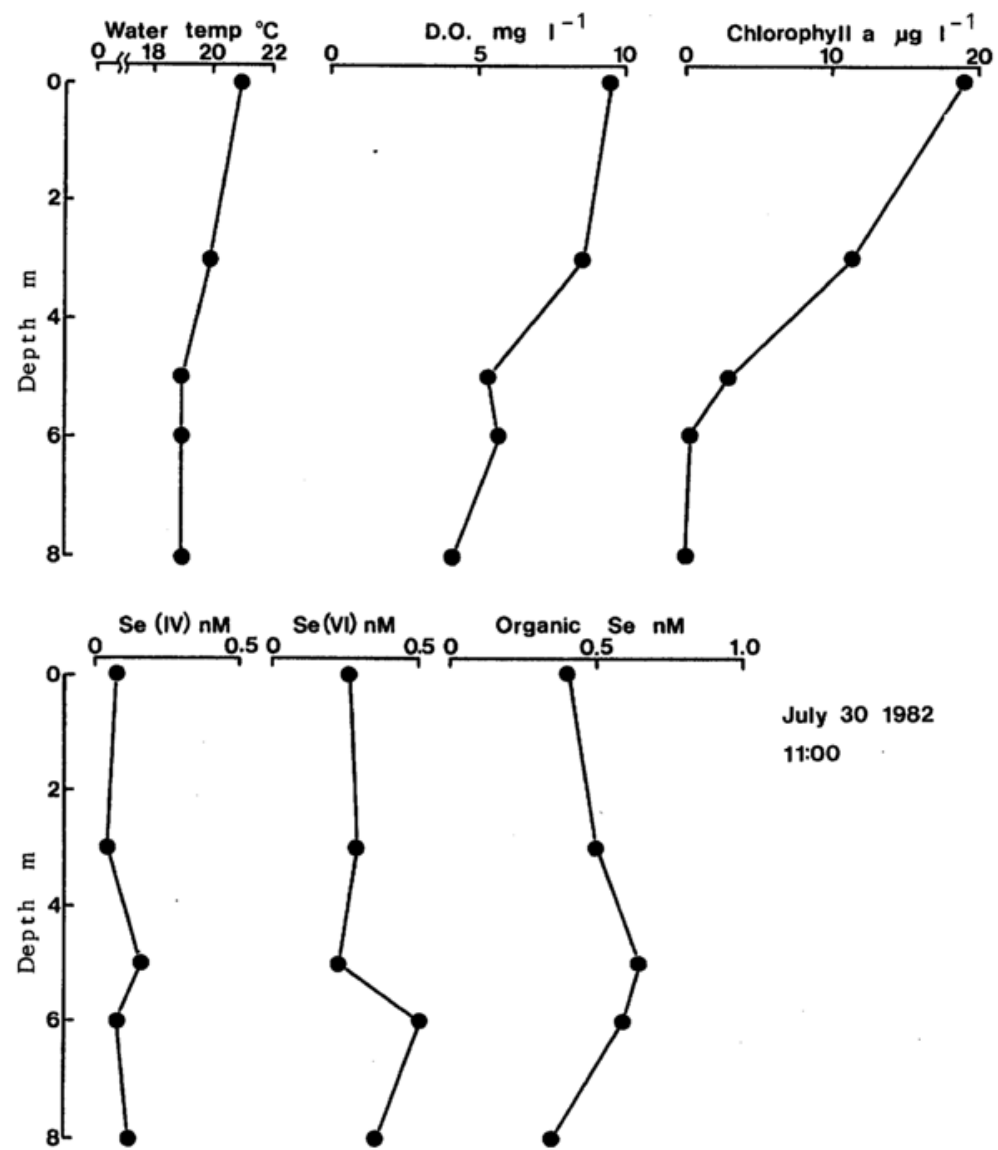

July 301982 11:00

Fig. 6. Vertical distributions of water temperature, dissolved oxygen, chlorophyll a, selenium (IV), selenium (VI) and organic selenium at station 15.

This may be due to the difference of chemical properties between selenium (IV) and selenium (VI). Since selenium (IV) is known to be easily adsorbed onto ferric hydroxide (Geering et al., 1968), a major carrier phase in estuaries, its adsorption onto suspended particles may be also a possible removal mechanism. On the other hand, selenlum (VI) was not adsorbed onto suspended particles. Therefore, selenium (VI) is chemically stable as compared with selenium (IV) in estuaries. In addition, Takayanagi and Wong (1984) reported that selenium (IV) is the predominant species of selenium in river waters and the concentration ratio of selenium (IV) to selenium (VI) decreases with increasing salinity. They pointed out that selenium (IV) is oxidized to selenium (VI) by aerobic bacteria in low salinity regions. The increase of selenium (VI) at the estuary might be due to the oxidation of selenium (IV) to selenium (VI) by microorganisms.

\section{Selenium in Osaka Bay}

Figure 6 shows the vertical profiles of water temperature, dissolved oxygen, chlorophyll a, selenium (IV), selenium (VI) and organic selenium at station 15 .

A temporary increase of selenium (IV) was observed at $5 \mathrm{~m}$. Selenium (VI) was uniformly distributed from the surface to $5 \mathrm{~m}$. Below this depth, the concentration increased rapidly to $0.50 \mathrm{nM}$ at $6 \mathrm{~m}$, then decreased to $0.35 \mathrm{nM}$ at the bottom. The concentration of organic selenium increased gradually from $0.40 \mathrm{nM}$ at the surface to $0.65 \mathrm{nM}$ at $5 \mathrm{~m}$, then decreased gradually towards the bottom. The concentrations of 

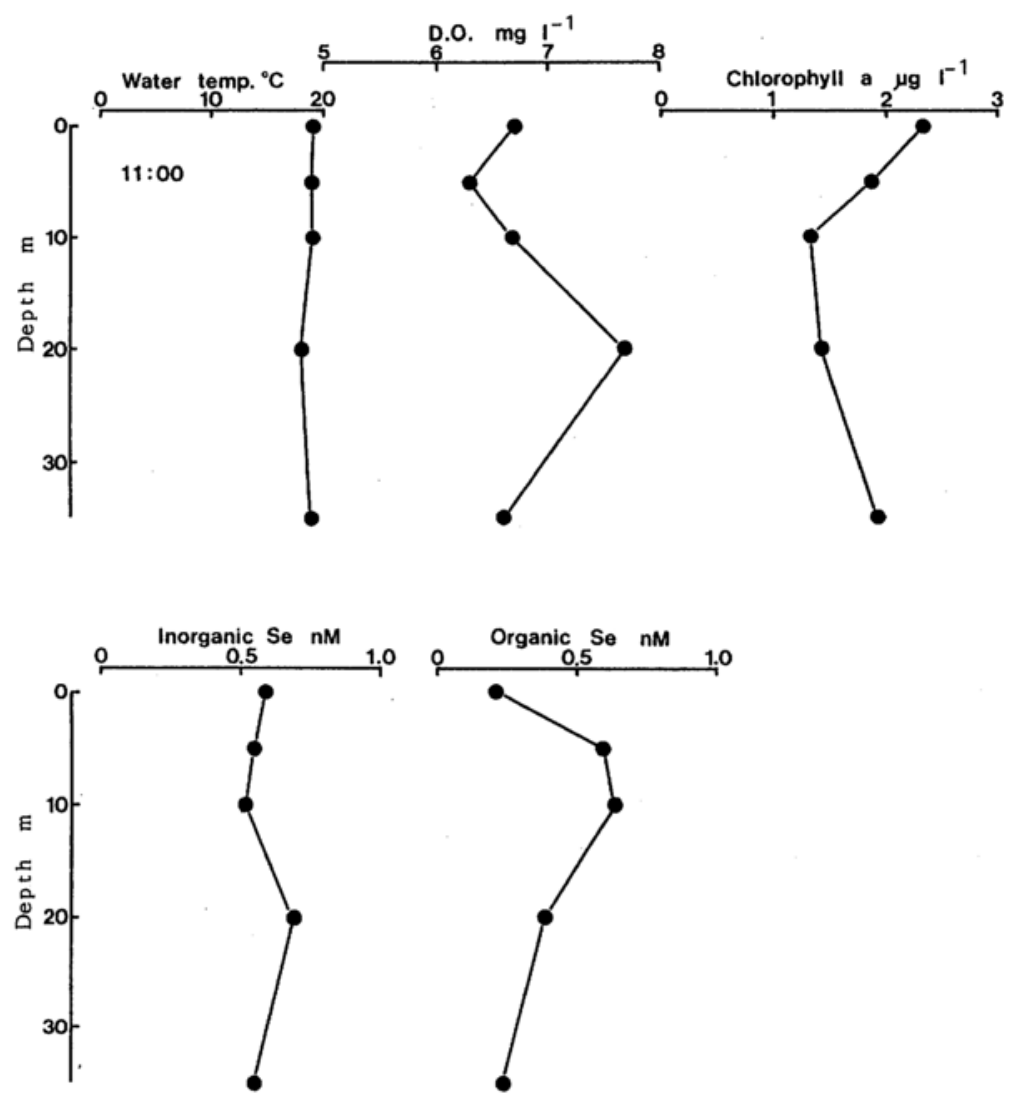

Fig. 7. Vertical distributions of water temperature, dissolved oxygen, chlorophyll a, inorganic selenium and organic selenium at station 16.

selenium (IV), selenium (VI) and organic selenium ranged from 0.05 to 0.16 , from 0.23 to 0.50 and from 0.40 to $0.65 \mathrm{nM}$, respectively. Cutter and Bruland (1984) reported that the distribution and speciation of dissolved selenium in the eastern tropical North Pacific Ocean, the concentrations of selenium (IV), selenium (VI) and organic selenium ranged from 0.02 to 1.03 , from 0.13 to 1.48 and from 0.01 to $1.06 \mathrm{nM}$, respectively. The concentrations of the three selenium species at St. 15 were lower than those in the North Pacific Ocean. In November 1981 at station 16 , water was sampled at three times, at 11:00, 13:00, 16:00. Figure 7 shows the vertical profiles of water temperature, dissolved oxygen, chlorophyll a, inorganic selenium and organic selenium at 11:00. The water temperature and inorganic selenium were uniformly distributed at each sampling time. The variation of inorganic selenium was smaller than that of organic selenlum. Organic selenium was not uniformly distributed at each sampling time.

\section{Conclusions}

The concentrations of selenium species in Lake Biwa, Yodo River and Osaka Bay, and the diurnal change of selenium in Osaka Bay were investigated. The results are summarized as follows.

1. Inorganic selenium (IV) and (VI) were uniformly distributed on each sampling day in Lake Biwa. However, in July when the thermocline appeared, the concentration of organic selenium was highest at the depth of the maximal chlorophyll a concentration.

2. The variation in the concentrations of selenium (IV) and (VI) from Lake Biwa to Osaka 
Bay was smaller than that of organic selenium. Organic selenium in the Yodo River occupied about $57 \%$ of the total dissolved selenium. A temporary increase of selenium (VI) in the estuary was observed.

3. The vertical distribution of organic selenium in Osaka Bay varied with sampling time.

Acknowledgments-We would like to thank Mr. Y. Fukunaga, Mr. T. Yoshida, Mr. T. Nagasawa, Ms. M. Kagawa and Ms. R. Komeda of Kinki University. Financial support from the Ministry of Education, Science and Culture, Japanese Government, and from Kinki University is gratefully acknowledged.

\section{REFERENCES}

Aono, T., Nakaguchi, Y., Hiraki, K., and Nagai, T. (1990) Determination of seleno-amino acid in natural water samples. Geochem. J. 24, 255-261.

Aono, T., Nakaguchi, Y., and Hiraki, K. (1991) Vertical profiles of dissolved selenium in the North Pacific. Geochem. J. 25, 45-55.

Carpenter, J. H. (1965): The accuracy of the Winkler method for dissolved oxygen analysis. Limnol. Oceanogr. 10, 135-140.

Cutter, G. A. and Bruland, K. W. (1984) The marine bio-geochemistry of selenium; A re-evaluation. Limnol. Oceanogr. 29, 1179-1192.

Fujinaga, T. and Hori, T. (1982) Biwako no kankyoukagaku, 1-4, Nihongakujyutushinkokai, Tokyo (Japanese).

Geering, H. R., Cary, E. E., Jones, L. H. P. and Allaway, W. H. (1968) Solubility and redox criteria for the possible forms of selenium in soils. Soil Science Society of American Proceedings, 32, 3540.

Ishimaru, T., Takeuchi, T., Fukuyo, Y. and Kodama, M. (1989) The selenium requirement of Gymnodinium Nagasakiense. Red tides: Biology, environmental science, and toxicology, (Okaichi, Anderson and Nemoto eds.) 357-360, Elsevier, London.

Kotoda, K. and Mizuyama, T. (1984) Water balance. Lake Biwa, (Hori, S. ed.) 165-174, Dr. W. Junk publishers, Dordrecht/Boston/Lancaster.

Lansche, A. M. (1967) Selenium and Tellurium-A Materials Survey. U.S. Bureau of Mines Information Circular No. 8340. Washington D.C., 55 pp.
Measures, C. I. and Burton, J. D. (1978) Behavior and speciation of dissolved selenium in estuarine water. Nature 273, 293-295.

Nakaguchi, Y., Hiraki, K., Tamari, Y., Fukunaga, Y., Nishikawa, Y. and Shigematsu, T. (1985) Fluorometric determination of inorganic selenium (IV), selenium (VI) and organic selenium in natural water. Anal. Sci. 1, 247-252.

Nakamura, Y., Umemori, T. and Watanabe, M. (1989) Chemical environment for red tide due to Chattonella antiqua. Part 2. Daily monitoring of the marine environment throughout the outbreak period. J. Oceanogr. Soc. Japan 45, 116-128.

Okamoto, I. (1984) Water currents. Lake Biwa, (Hori, S. ed.) 174-183, Dr W. Junk publishers, Dordrecht/Boston/Lancaster.

Strickland, J. D. H. and Parsons, T. R. (1972) A practical handbook of sea water analysis. Bull. Fisher. Res. Board Canada No. 167, 2nd edn. Ottawa, 311 pp.

Sugimura, Y. and Suzuki, Y. (1985) A method of chemical speciation of metallic elements dissolved in sea water by using XAD-2 resin. Pap. Met. Geophys. 36, 187-207.

Sugiyama, M., Fujino, O., Kihara, S. and Matsui, M. (1986) preconcentration by dithiocarbamate extraction for determination of trace elements in natural waters by inductively-coupled plasma atomic emission spectrometry. Anal. Chim. Acta. 181, 159168.

Takayanagi, K. K. and Benlzile, N. (1988) Profiles of dissolved and acid-leachable selenium in a sediment core from the lower St. Lawrence estuary. Mar. Chem. 24, 307-314.

Takayanagi, K. K. and Cossa, D. (1985) Speciation of dissolved selenium in the upper St. Lawrence estuary. Marine and Estuarine Geochemistry, (Sigleo and Hattori eds.) 275-284, Lewis Publisher, Inc., Chelsea, MI.

Takayanagi, K. K. and Wong, G. T. F. (1984) Total selenium and selenium (IV) in the James river estuary and southern Chesapeake Bay. Estuarine, Coastal and Shelf Sci. 18, 113-119.

Takayanagi, K. K. and Wong, G. T. F. (1985) Dissolved inorganic and organic selenium in the Orca Basin. Geochim. Cosmochim. Acta. 49, 539-546.

Yamochi, S. (1983) Mechanisms for outbreak of Heterosigma akashiwo red tide in Osaka Bay, Japan. Part 1 Nutrient factors involved in controlling the growth of Heterosigma akashiwo hada, $J$. Oceanogr. Soc. Japan 39, 310-316. 